
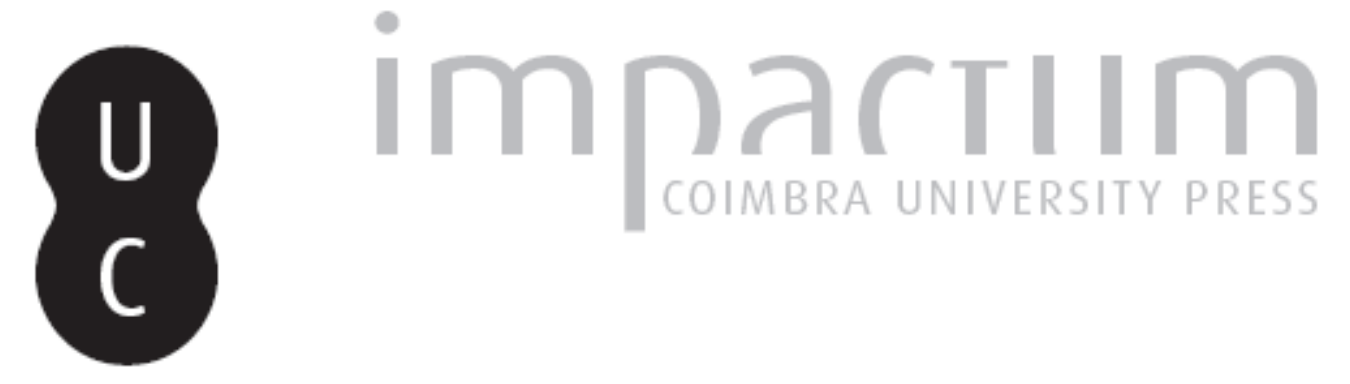

\title{
Da epigrafia votiva de Conimbriga: observações e novos monumentos
}

Autor(es): Garcia, José Manuel

Publicado por: Imprensa da Universidade de Coimbra

URL persistente:

URI:http://hdl.handle.net/10316.2/45596

DOI:

DOI:https://dx.doi.org/10.14195/1647-8657_26_2

Accessed : $\quad$ 26-Apr-2023 10:47:22

A navegação consulta e descarregamento dos títulos inseridos nas Bibliotecas Digitais UC Digitalis, UC Pombalina e UC Impactum, pressupõem a aceitação plena e sem reservas dos Termos e Condições de Uso destas Bibliotecas Digitais, disponíveis em https://digitalis.uc.pt/pt-pt/termos.

Conforme exposto nos referidos Termos e Condições de Uso, o descarregamento de títulos de acesso restrito requer uma licença válida de autorização devendo o utilizador aceder ao(s) documento(s) a partir de um endereço de IP da instituição detentora da supramencionada licença.

Ao utilizador é apenas permitido o descarregamento para uso pessoal, pelo que o emprego do(s) título(s) descarregado(s) para outro fim, designadamente comercial, carece de autorização do respetivo autor ou editor da obra.

Na medida em que todas as obras da UC Digitalis se encontram protegidas pelo Código do Direito de Autor e Direitos Conexos e demais legislação aplicável, toda a cópia, parcial ou total, deste documento, nos casos em que é legalmente admitida, deverá conter ou fazer-se acompanhar por este aviso.

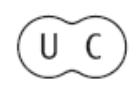


FACULDADE DE LETRAS

INSTITUTO DE ARQUEOLOGIA

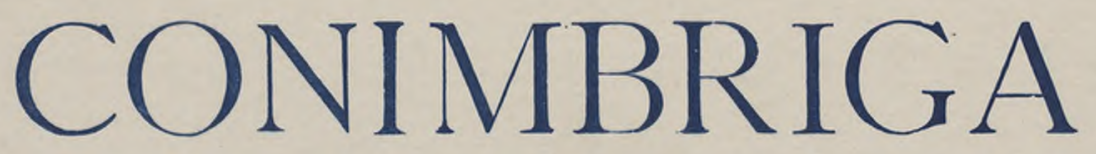

VOLUME XXVI

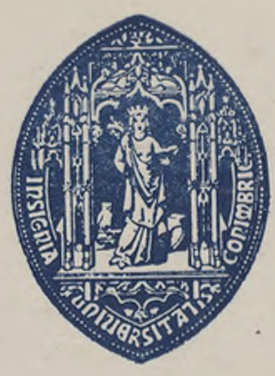

UNIVERSIDADE DE COIMBRA

1987 
José Manuel Garcia

Investigador

\section{DA EPIGRAFIA VOTIVA DE CONIMBRIGA}

\section{- OBSERVAÇÕES E NOVOS MONUMENTOS}

«Conimbriga», XXVI (1987), p. 39-59

Resumo: Alguns dos monumentos epigráficos que testemunham as religiões de Conimbriga põem questões que concernem quer a forma de proceder à interpretação de certas peças quer a identificação de novos textos.

Vergilio Correia, que sempre se interessou pelo estudo de Conimbriga, publicou um artigo, em 1943, onde se refere às várias inscrições votivas que então conhecia naquela cidade lusitano-romana. Sobre algumas delas não ficou qualquer outro testemunho, até que, recentemente, se identificaram no Museu Nacional de Arqueologia e Etnologia em Lisboa, dois dos monumentos por ele referidos como sendo consagrados L(aribus) Aquitibus e Minerva. Junto dessas árulas estavam duas outras semelhantes que também devem ser provenientes de Conimbriga: Aquiae e I(ovi) O(ptimo) $M($ aximo).

RÉSUMÉ: Quelques-uns des monuments épigraphiques qui témoignent les réligions anciennes de Conimbriga posent des problèmes concernant soit la forme de faire l'intérpretation de certaines pièces, soit l'identification de nouveaux textes.

Vergilio Correia, qui s'est toujours intéressé à l'étude de Conimbriga, a publié un article, en 1943, qui concerne plusieurs inscriptions votives qu'il connaissait à l'époque dans cette ville lusitano-romaine. Aucun autre témoignage n'est resté sur quelques-unes de ces inscriptions, jusqu'à ce que récemment on a identifié au Museu Nacional de Arqueologia e Etnologia, à Lisbonne, deux de ces monuments auxquels il avait fait référence comme étant consacrés: L(aribus) Aquitibus et Minerva. Tout près de ces petits autels se trouvaient deux autres pièces semblables qui doivent provenir de Conimbriga. L'une est dediée à Aquiae et l'autre à $I$ (ovi) $O$ (ptimo) M(aximo). 
(Página deixada propositadamente em branco) 


\section{DA EPIGRAFIA VOTIVA DE CONIMBRIGA — OBSERVAÇÕES E NOVOS MONUMENTOS}

A Epigrafia é uma ciência histórica que requer uma grande abertura crítica e necessita de uma constante atitude de revisão, quer no apuramento e estabelecimento correcto dos textos, quer no seu levantamento e ordenamento sistemáticos. Ilustrando estas observações, iremos tecer algumas considerações sobre a epigrafia votiva de Conimbriga.

1. Vergilio Correia e a epigrafia votiva de Conimbriga

A 24 de Maio de 1943, Vergilio Correia publicou no suplemento ao n. ${ }^{\circ} 4375$ do «Diário de Coimbra», jornal que então dirigia, um artigo intitulado Divindades romanas de Conimbriga ( $\left.{ }^{(}\right)$. Tratava-se de um estudo panorâmico em que o autor procurava divulgar as informações de que dispunha relativamente aos testemunhos das religiões antigas que até então haviam sido reveladas em Conimbriga.

(1) É de notar que, por qualquer lapso, este interessante artigo escapou à muito bem inventariada Bibliografia de Vergilio Correia; 1909-1944, preparada por Maria Teresa Pinto Mendes (Coimbra, Biblioteca Geral da Universidade, 1970), onde só muito poucos títulos faltam no levantamento da vastíssima obra de Vergilio Correia. Felizmente, Jorge de Alarcão detectou-o e pôde inseri-lo nas Obras, IV, p. 327-330. Neste volume são reunidos, de forma criteriosa, quase todos os trabalhos consagrados à Arqueologia por Vergilio Correia. Os poucos que não são incluídos encontram-se referidos no prefácio da obra ou na citada Bibliografia.

Conimbriga, 26 (1987), 39-59 
O interesse de Vergilio Correia por Conimbriga era muito anterior, pois a sua longa lista de estudos históricos, arqueológicos e artísticos inicia-se em 1909, precisamente com a publicação de um artigo intitulado: De Conimbriga, Achados vários - uma fíbula ${ }^{(2)}$.

Conimbriga era um dos alvos preferidos das suas visitas de estudante, revelando-se dessa forma o entusiasmo pelo estudo da Arqueologia. No fim de 1909, recolheu alguns testemunhos anteriores à romanização de Conimbriga, que o conduziram, em 1912, no ano em que se tornara conservador do Museu Etnológico, à realização de uma sondagem nas ruínas. Os resultados dessa exploração foram por ele publicados em 1916 no artigo Conimbriga. A camada pré-romana da cidade (notas de uma exploração de 10 dias em Condeixa-a-Velha $\left({ }^{3}\right)$.

Segue-se um período em que não se detectam sinais de actividade de Vergilio Correia em Conimbriga. Entretanto, foi nomeado, em 1921, professor de História de Arte e Arqueologia na Faculdade de Letras da Universidade de Coimbra e só em 1929 é que reiniciou os trabalhos arqueológicos, que continuou até à data da sua morte, em 1944.

Os resultados das pesquisas nesta fase das suas actividades nunca foram alvo de relatórios muito pormenorizados. Vergilio Correia limitou-se a publicar, em 1935, um opúsculo genérico sobre Conimbriga $\left({ }^{4}\right)$ e vários artigos de pequenas proporções, de entre os quais cabe destacar o que publicou em 1941 em Espanha, com o título: Las más recientes excavaciones romanas de interés en Portugal. La ciudad de Conimbriga $\left({ }^{5}\right)$.

O artigo publicado em 1943, a que nos referimos mais atrás, foi um dos últimos que consagrou a Conimbriga, tendo com ele deixado

(2) AP, XIV, 1909, p. 259-261 (=Obras, IV, p. 287-289).

(3) AP, XXI, 1916, p. 252-264 (= Obras, IV, p. 292-303). Note-se que Vergilio Correia abandonara o Museu Etnológico em 1915.

(4) Este trabalho intitulava-se Conimbriga, Notícia do oppidum e das escavações nele realizadas. Teve novas edições em 1936 e 1938. O seu teor foi bastante revisto depois de 1941 e saiu postumamente, em 1945, um opúsculo só com o título Conimbriga, que teve várias edições, encontrando-se integrado nas Obras, IV, p. 309-318.

(5) «Archivo Español de Arqueologia», XIV, 1940-1941, p. 257-267. 
em aberto algumas questões que não têm sido devidamente consideradas.

Hoje, mais não podemos fazer do que lamentar que a falta de disponibilidade e a morte de Vergilio Correia o tivessem impossibilitado de aprofundar as referências que nos aparecem enigmáticas em algumas frases muito lacónicas. A algumas dezenas de anos da redacção e publicação das Divindades romanas de Conimbriga, apenas se torna possível a espinhosa missão de analisar criticamente um texto que coloca várias questões.

Quando, em 1929, Vergilio Correia reiniciou as pesquisas arqueológicas em Conimbriga, só havia três referências a divindades. A mais antiga reportava-se a uma lápide descoberta em 1815 e desaparecida pouco tempo depois, onde se tem admitido a existência de uma consagração ao deus Neto $\left(^{6}\right)$. É de assinalar que Vergilio Correia nunca se lhe refere. A outra inscrição votiva de Conimbriga conhecida então era dedicada a Apoio Augusto. Foi revelada em 1919 e, embora o seu paradeiro actual também seja desconhecido, há dela uma boa fotografia e não há reservas sobre a sua interpretação ${ }^{7}$ ). Vergilio Correia faz-lhe apenas uma breve referência. Finalmente, era de há muito conhecida uma ara Dis Deabusq(ue) Coniumbrig(ensium?) encontrada em Numão $\left({ }^{8}\right)$, embora Vergilio Correia se lhe refira várias vezes como sendo de Freixo de Numão (na sequência de E. Hübner). Também admitiu como sendo de Conimbriga uma ara Laribus Patriis que, na verdade, foi encontrada a 50 metros de Vale de Remigio, Mortágua $\left({ }^{9}\right)$.

No artigo de 1943 afirmou, na sequência de observações à ara de Mortágua e aos Lares e Ninfas (que considerava estarem compreendidos entre os Dii Deaeq(ue) Coniumbrig\{ensium?) da ara de Numão), que eram "vulgares em Conimbriga as inscrições aos Lares», realçando mesmo que «é essa uma das grandes riquezas da epigrafia local», continuando depois por observar que são «quase todas

$\left(^{6}\right)$ CIL II 365; Fouilles II, n. ${ }^{\circ} 15$; RAP 175.

(7) António G. R. Madahil, Uma ara inédita, AP, XXIV, 1919-1920, p. 197-198; Fouilles II, n. ${ }^{\circ} 2$; RAP 238.

(8) CIL II 432; Fouilles II, n. ${ }^{\circ}$ 3; RAP 201.

$\left({ }^{9}\right)$ Fouilles II, p. 48-49; RAP 380. 
lavradas em aras ou árulas de calcário de trabalho muito cuidado. Entre elas [o sublinhado é nosso] convém citar a consagrada $L$ (aribus) Aquitibus que apareceu no tanque da sala da fonte do palácio extra-muros. Fora do palácio, nas terras a nascente dele,

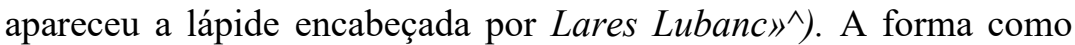
redigiu as primeiras frases dá a entender que conhecia outras inscrições de Conimbriga relativas aos Lares, mas tal suspeita é difícil de provar. Duas inscrições aos Lares em Conimbriga só foram reveladas em $1967{ }^{(u)}$.

Quanto à árula L(aribus) Aquitibus descoberta em 1939, e só agora localizada, já havia sido noticiada em 1941, também de forma sintética e sem o texto completo (12). A lápide aos Lares Lubanc(i) fora descoberta em 1938 e também publicada em 1941, quando ainda se encontrava no Museu Machado de Castro (13).

Retomando o teor do artigo de 1943, verificamos que, depois das considerações sobre os Lares, Vergilio Correia aborda o culto do Génio, afirmando peremptoriamente o seguinte $\left({ }^{14}\right)$ :

«Há em Conimbriga árulas caseiras encabeçadas pela dedicatória: Genio».

Temos de confessar que esta frase nos deixa perplexos. Na verdade, só em 1965 é que foi assinalada uma consagração Genio Conimbricae ( $\left.{ }^{15}\right)$. Perante esta circunstância, somos levados a supor que houve mais peças consagradas ao Genius em Conimbriga, pois não nos parece próprio de Vergilio Correia a invenção de peças que

(10) Obras, IV, p. 328.

(u) Le culte, p. 213-217 e p. 223, n. 10.

(u) No artigo citado na n. 5. Na versão incompleta, vide Fouilles //, n. ${ }^{\circ}$; p para a versão completa, RAP 588.

(13) Catálogo-Guia; Secção de Arte e Arqueologia; Museu Machado de Castro, Coimbra, 1941, p. 11. Para esta inscrição, veja-se: Fouilles //, n. ${ }^{\circ} 11$; RAP 210.

(14) Obras, IV, p. 329.

(15) R. Étienne e J. M. Bairrão Oleiro, Resultados da primeira campanha de escavações luso-fr anees as em Conimbriga, s. 1., Museu Monográfico de Conimbriga, 1966, p. 15. Trata-se da inscrição publicada em Fouilles II, n. ${ }^{\circ} 6$ e em RAP 203. 
não existissem. Poderá, talvez, haver outra justificação para uma notícia tão lacónica, mas a hipótese de que tivessem levado sumisso tem de se colocar neste momento.

Depois desta intrigante passagem, Vergilio Correia refere-se, pela primeira vez, à árula Libero Patri, «que foi encontrada no terreno que a Faculdade de Letras adquiriu no centro de Conimbriga em 1929» (16). É a única inscrição de que apresenta leitura completa, a medida da altura e uma fotografia (no «Diário de Coimbra»). É de lamentar que não tenha tido a mesma atitude em relação a todos os testemunhos a que se referira anteriormente e àqueles a que alude no fim do artigo. Embora realcemos aqui o grande valor científico da obra de Vergilio Correia, temos de reconhecer que a Epigrafia nunca lhe mereceu uma atenção muito particular.

Depois de se ter detido com um certo cuidado sobre a inscrição ao Liber Pater, Vergilio Correia surpreende-nos com o seguinte parágrafo que remata o artigo, deixando-nos cheios de interrogações $\left({ }^{17}\right)$ :

«O culto de Marte, Vénus, Esculápio e Apolo está em Conimbriga documentado por inscrições, e o de Minerva por uma árula e uma estatueta de bronze de delicada escultura».

Vergilio Correia não teve aqui em conta a inscrição Remetibus $\operatorname{Aug}(. .$.$) que descobrira em 1936$ e a que já se referira em $1941\left({ }^{18}\right)$.

A inscrição a Marte a que alude foi por ele apresentada sumariamente em 1941, sem se referir nem à data nem ao local exacto de descoberta $\left({ }^{19}\right)$.

A referência a Apoio reporta-se, certamente, à inscrição revelada em 1919 por Madail $\left({ }^{20}\right)$.

(16) Obras, IV, p. 329. É a inscrição publicada em Fouilles //, n. ${ }^{\circ} 13$ e em RAP 389.

(17) Obras, IV, p. 330.

(18) Catálogo-Guia..., p. 2 e Obras, IV, p. 314. Publicada em Fouilles IL n. ${ }^{\circ} 14$ e em RAP 395.

(19) Catálogo-Guia..., p. 11.

$\left(2^{\circ}\right)$ Veja-se a nota 7. Não pensamos como R. Étienne e G. Fabre, Fouilles II, P- 37 (e 37 n. 138) que: «V. Correia faisait allusion à ce culte sans

Conimbriga, 26 (1987), 39-59 
Se estas informações estão bem confirmadas, as restantes são mais problemáticas. Felizmente, para uma delas julgamos ter encontrado a solução com a localização da árula a Minerva. Mais difíceis de resolver são as questões colocadas pela alusão às inscrições que atestam o culto a Vénus e Esculápio. Aparentemente terão desaparecido, pois não há mais nenhuma referência a tais peças. Ainda assim, para o caso de Esculápio, não podemos deixar de colocar, sob prudente reserva, uma hipótese que nos parece plausível. Consiste ela numa leitura apressada e errada de Vergilio Correia da árula que apresentamos mais à frente e que interpretamos como consagrada a Aquiae. Aquele autor poderia ter lido (ou querido 1er) na inscrição Asclepio, em vez de mais uma estranha divindade indígena.

Consideramos todas estas observações preliminares necessárias para uma melhor compreensão e enquadramento das quatro árulas que apresentamos no ponto seguinte.

\section{Quatro árulas}

Quando, em 1986, realizávamos pesquisas sobre a epigrafia votiva lusitano-romana do Museu Nacional de Arqueologia e Etnologia (21), deparámos com um conjunto de quatro árulas que não estavam inventariadas nem tinham qualquer referência de origem. Ao analisá-las, contudo, foi fácil determinar que a respectiva proveniência deveria ser Conimbriga ou, pelo menos, esta era certa para duas delas. Tal conclusão derivava do facto de numa se 1 er claramente L. AQVITIBVS e noutra se 1 er com segurança, na primeira linha, MINERVA. Para as outras duas

apporter de référence particulière». Neste caso, não era absolutamente necessária pois a inscrição estava bem referenciada.

(21) Tal estudo teve em vista a preparação do volume das Religiões antigas de Portugal — Fontes epigráficas, Lisboa, Imprensa Nacional-Casa da Moeda (no prelo). Uma primeira notícia da redescoberta das árulas foi enviada para a revista «Al-madan», inserida no artigo Observações sobre uma inscrição de Lisouros (CIL II 5069) e árulas de Conimbriga. 
peças não havia qualquer indicação, mas parece-nos viável admitir a mesma proveniência para o conjunto. Para o caso da árula Aquiete, poderia haver maior segurança se a hipótese de confusão deste nome com Asclepio, referido por Vergilio Correia, estivesse certa. A análise petrográfica do material desta peça, bem como do material do fragmento da quarta árula, de que também não há nenhuma referência, poderão viabilizar (ou não) esta sugestão de localização. Deve-se ainda ter em conta a semelhança tipológica destes monumentos com as restantes árulas de Conimbriga.

O conhecimento cabal e o paradeiro destas peças foi desconhecido dos vários investigadores que, em datas recentes, têm tratado da epigrafia lusitano-romana de Portugal. Na verdade, trata-se de uma localização insólita para materiais que deveriam ter ficado em Coimbra ou em Conimbriga.

Sobre a forma como vieram parar ao Museu Nacional de Arqueologia e Etnologia ainda não foi possível obter informações elucidativas. Seria desejável que alguma referência ou carta, que pessoalmente desconhecemos, fizesse um pouco de luz sobre este pequeno mistério.

À falta de melhores perspectivas, admitimos, porém, que a vinda de quatro árulas para o Museu possa ter ocorrido sob a direcção de Manuel Heleno, período em que se verificou a entrada de grande quantidade de materiais arqueológicos, muitos dos quais ficaram por catalogar, como poderia ter sido o caso.

$\mathrm{Na}$ rápida pesquisa bibliográfica que fizemos, pudemos encontrar informações de João L. Saavedra Machado ( ${ }^{22}$ ), que talvez revelem alguma pista para determinar a deslocação de tais peças para Lisboa. Segundo aquele autor (23), Manuel Heleno em 1939 «foi em missão particular visitar a colecção do Prof. Vergilio Correia». Teria Vergilio Correia cedido as peças para estudo e, como entretanto morreu, não foram devolvidas? Outra sugestão, tão delicada como a anterior, poderá relacionar-se com a notícia de que, em 1945, Manuel Heleno «foi oficialmente em excursão a Coimbra»,

(22) Subsídios para a história do Museu do Dr. Leite de Vasconcelos, AP, 2. a série, V, 1964, p. 51-448.

(23) Ob. eit., p. 125.

Conimbriga, 26 (1987), 39-59 
visitou, entre outros locais, o Museu Machado de Castro e «desempenhou a incumbência de colher elementos de informação sobre o desvio de objectos e propor as medidas necessárias» $\left({ }^{24}\right)$.

Vejamos agora os dados essenciais e os delicados problemas de leitura que as quatro árulas colocam. Aliás, as dificuldades com que deparámos para interpretar os seus textos devem ter sido um dos factores essenciais que impediram até agora o seu cabal conhecimento.

Árula de calcário.

Dimensões ( $\left.{ }^{25}\right): 18,5$ X 8 X 6; a. 1. : 0,6/1,2.

L(aribus) / AQVITIBV[S] / G(aius) C\{aecilius?) RVF[V]S / $\mathrm{A}$ (nimo) L(ibens) Y(otum) $\mathrm{S}$ (olvit)

É de salientar o grande espaço existente entre as linhas 2 e 3 desta inscrição, que não apresenta qualquer dificuldade de leitura. Vergilio Correia talvez não a tenha publicado integralmente por causa da sigla do nomen, ou apenas porque não lhe apareceu conveniente divulgá-la.

Há, apenas, duas dificuldades de interpretação neste texto. Uma consiste na necessidade de uma certa reserva face à sigla inicial, seguida de um punctus, a qual, apesar de tudo, acreditamos desdobrável em Laribus como fizeram Vergilio Correia e outros autores. Quanto ao nomen do dedicante, ele poderá ser Caecilius (26), Claudius ou outro que fosse muito conhecido.

Rufus é cognomen muito divulgado em Conimbriga.

Seja qual for o gentilicio do dedicante, o seu nome passa a estar ligado ao belo «palácio dos repuxos» onde aparecera a árula.

(24) Ob. cit., p. 137.

(25) São dadas em centímetros e referem-se apenas às medidas máximas pela ordem: altura, largura, espessura; a. 1. = Altura das letras.

(26) A dedicante da árula consagrada a Apoio já referida (vide nota 7) é uma Caecilia Avita. 


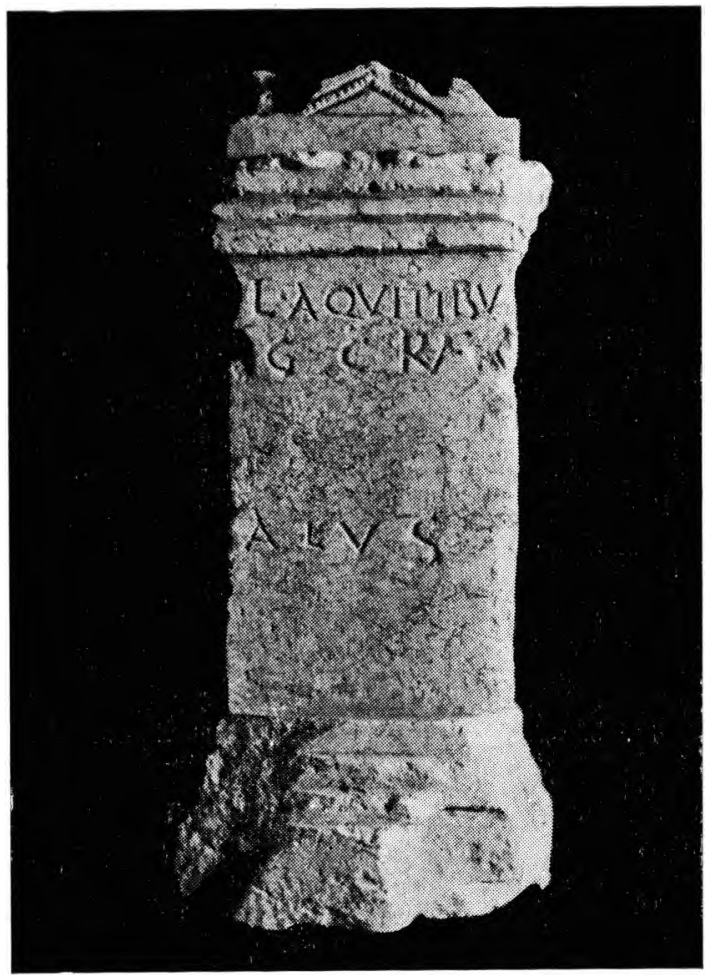

FIG. 1

Conimbriga, 26 (1987), 39-59 
Àmia de calcário.

Dimensões: 20 X 8 x 6; a. L: 0,7/1,3.

MINERVA[E?] / SANGRAE [?] / [...]LLECIA[...] / ARC (?) $\mathrm{AR}[\ldots]$.. DONVM/DE $<\mathrm{D}>\mathrm{IT} \mathrm{M}$ [evito)

O campo epigráfico encontra-se afectado nalguns pontos, facto que dificulta uma apreciação correcta do texto gravado.

Nal. 1, as únicas letras afectadas são a terceira e a sétima. Julgamos que esta (um A) poderá ser a última letra da linha, devido ao reduzido espaço que haveria à direita. Apesar de tudo, não se pode excluir a hipótese de que tenha havido um $\mathrm{E}$ final, para formar o dativo da maneira mais frequente (talvez em nexo com o A).

$\mathrm{Na}$ 1. 2, as letras são de leitura clara. Admitimos a hipótese de que Sangrae possa ser um epíteto indígena da divindade, mas há que manter alguma reserva, pois poder-se-ia também ter dado o caso de o lapicida ter querido escrever Sanctae Sacrum, confundindo as linhas do texto manuscrito que lhe fora apresentado.

$\mathrm{Na}$ 1. 3, teria havido inicialmente uma letra (no máximo duas), o mesmo acontecendo no fim. Trata-se, seguramente, do nome do(a) dedicante, que apresenta afinidades com o gentilicio Alleicea registado num monumento que se guarda no Museu Nacional de Machado de Castro, em Coimbra (CIL II 5241).

$\mathrm{Na} \mathrm{1.} \mathrm{4,} \mathrm{falta} \mathrm{a} \mathrm{terceira} \mathrm{letra,} \mathrm{que} \mathrm{nos} \mathrm{parece} \mathrm{apresentar} \mathrm{uma}$ curvatura, talvez um C. Um conimbrigense referido em monumento de Egitânia tem o gentilicio Allacarius (Fouilles II, n. ${ }^{\circ}$ 29), que poderá ter alguma relação com o antropònimo aqui registado.

No início da 1. 5, há um $\mathrm{D}$, depois $\mathrm{ONV}$ a que se segue $\mathrm{M}$.

A última linha começa com $\mathrm{DE}$, havendo a falta do $\mathrm{D}$ para completar a palavra DEDIT.

O teor completo da inscrição é difícil de apurar devido aos defeitos da conservação da peça nas 1.3 e 4 . O que é mais seguro e de evidente importância é a consagração à deusa Minerva, de que só conhecíamos em Portugal um testemunho epigráfico, em Valado (Alcobaça) $\left({ }^{27}\right)$.

(27) CIL II 351; RAP 410.

Conimbriga, 26 (1987), 39-59 


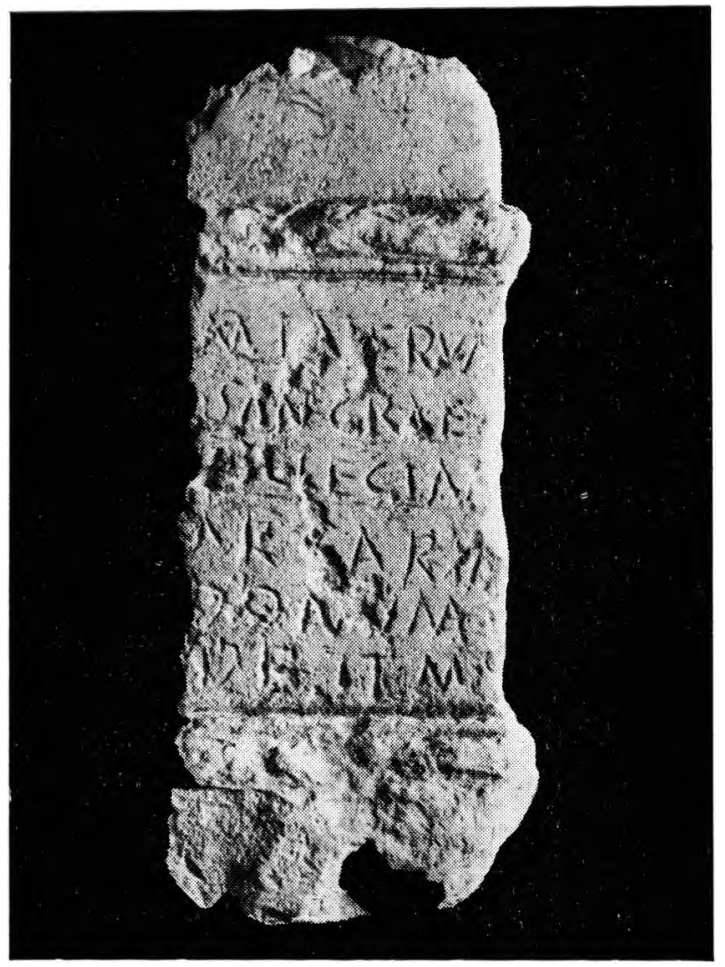

FIG. 2 
Parte superior de uma àrula de calcário.

Dimensões: $8,2 \times 6,5 \times 6$; a. $1 .: 0,5 / 1$.

AQVIAII / SACRVM / CICII[...]N[...] / VS [ ?] A[...]

Na nossa opinião, as duas primeiras linhas são claras, apesar de, na 1. 1, a gravação das letras apresentar algumas deficiências. O E está grafado sob a forma de dois traços verticais.

$\mathrm{Na}$ 1. 3, há a falta de uma ou duas letras antes do $\mathrm{N}$; segue-se-lhe uma outra letra que desapareceu.

$\mathrm{Na} 1.4$, a segunda letra poderá ser um $\mathrm{S}$.

Tal como na árula $n .^{\circ}$, não conseguimos vislumbrar o nome do dedicante.

\section{4}

Parte inferior de uma árula de calcário.

Dimensões: 12,5 x 9 × 6,5.

\section{[I(ovi)] O(ptimo) M(aximo) PIC/VS LVPV/S}

Embora falte o capitel da árula, parece-nos admissível que o texto esteja completo, pois não há vestígios de letras antes da 1. 1. Este facto pode reforçar-se tendo em conta as características da epígrafe.

As letras conservam-se um pouco gastas, mas legíveis. Da primeira que falta, nota-se ainda um ligeiro traço idêntico ao do I da 1. 1. Teríamos, assim, a sigla de lovi, a qual se coaduna perfeitamente com as duas letras seguintes OM.

Desta forma, uma consagração a Júpiter Óptimo Máximo em Conimbriga passa a ter um testemunho de carácter popular (carácter que a deficiente qualidade do trabalho epigráfico desta árula parece revelar).

O dedicante talvez pudesse ser Picus Lupus, não havendo fórmula votiva. 


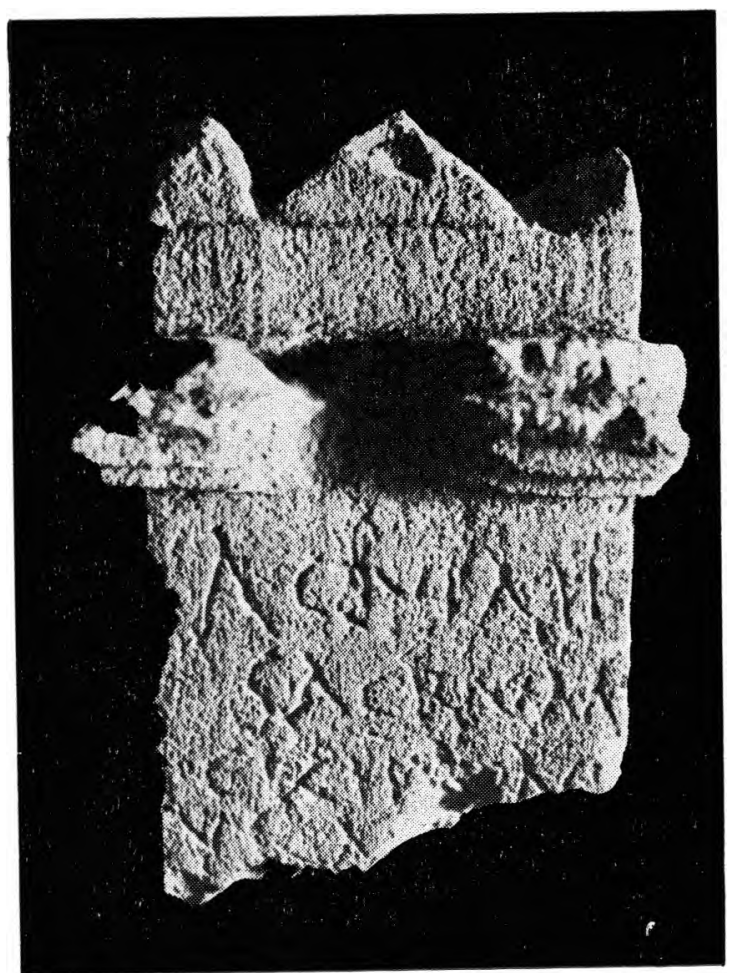

FIG. 3

Conimbriga, 26 (1987), 39-59 
Tendo em conta os textos 2 e 4, passaremos, pois, a considerar em Conimbriga a existência do culto à tríade capitolina, uma vez que o culto a Juno já estava bem assinalado.

\section{Mais algumas observações sobre a epigrafia votiva de Conimbriga}

Depois de termos chamado a atenção para os problemas do artigo de Vergilio Correia escrito em 1943 e apresentado alguns dados novos com ele relacionados, julgamos ainda importante avançar com algumas rápidas observações relativas ao conjunto da epigrafia votiva de Conimbriga.

É nossa convicção que só através de sucessivas e diversificadas abordagens dos textos epigráficos se torna possível um adequado e aperfeiçoado conhecimento das informações históricas que tais documentos fornecem.

Conimbriga é uma das poucas cidades de Portugal romano cujo acervo epigráfico foi alvo dum levantamento sistemático de grande rigor, levado a cabo por R. Étienne e G. Fabre $\left({ }^{2 S}\right)$. Estes autores realizaram uma obra notável, que se pode considerar verdadeiramente exemplar $\left({ }^{29}\right)$. Tal facto, contudo, não pode impedir, antes pelo contrário, a análise crítica de algumas considerações. Para além de não terem podido conhecer as informações referidas no ponto 2 , os autores das Fouilles II terão expresso, por vezes, pareceres que serão susceptíveis de alguma reserva ou que necessitam de maior prudência. Na verdade, há documentos que se apresentam de muito delicada interpretação.

R. Étienne e G. Fabre englobam vinte e três inscrições votivas no primeiro capítulo das Fouilles II, mas há que considerar que no corpus das inscrições encontradas em Conimbriga só se podem contar vinte e uma, pois uma é de Numão (n. ${ }^{\circ} 3$ ) e a outra de Mérida (n. ${ }^{\circ}$ 9). Como veremos mais à frente e face às dúvidas que nos levanta a atribuição à deusa Fortuna da inscrição n. ${ }^{\circ}$, a colecção de epigrafia

${ }^{(28)}$ Fouilles II.

${ }^{(29)}$ Em termos regionais, só se lhe equiparam os trabalhos feitos para a região coliponense por $\mathrm{D}$. Domingos de Pinho Brandão e, para os territórios a sul do Tejo, a monumental tese de José d'Encarnação. 


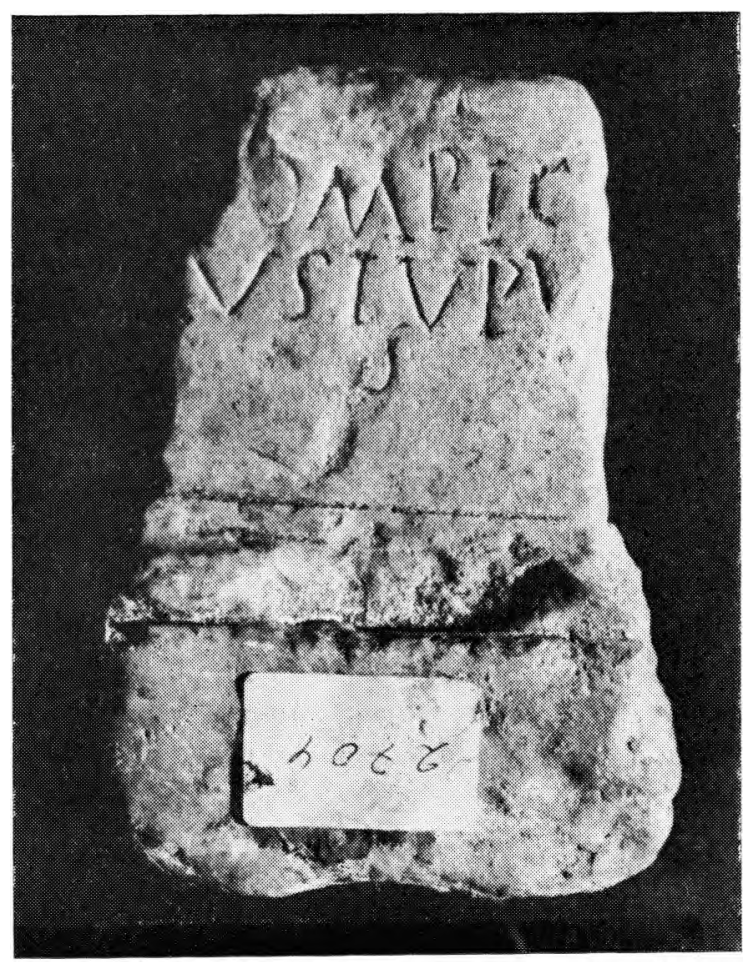

FI G. 4 
votiva de Conimbriga ficaria com vinte testemunhos. Como há a juntar-lhes o testemunho de Minerva atrás apontado, ficaremos com vinte e um testemunhos certos mais dois plausíveis que também já atrás apontámos.

Do conjunto reunido nas Fouilles II, há peças cuja interpretação não coloca questões de grande significado. É o caso das consagrações ( ${ }^{30}$ ) a Apollini (n. $\left.{ }^{\circ} 2\right)$; Fortunae (n. $\left.{ }^{\circ} 4\right)$; Genio Conimbricae (n. ${ }^{\circ}$ 6); Iunoni (n. ${ }^{\circ}$ 8); Fl(aviae) Conimbricae et Larib(us) eius (n. $\left.{ }^{\circ} 10\right)$; Lares Lubanc(os) (n. $\left.{ }^{\circ} 11\right) \mid$ Libero Patri (n. $\left.{ }^{\circ} 13\right) ;$ Marti Aug(usto) (n. ${ }^{\circ}$ 14); Pietati Aug(ustae) (n. ${ }^{\circ}$ 17); Remetibus Aug(ustis) (n. $\left.{ }^{\circ} 19\right)$ e dois fragmentos (n. ${ }^{\circ} 21$ e 23$)$.

Há casos, contudo, onde a interpretação dos documentos deverá ser acompanhada de um grau de reserva maior, devido às dúvidas que se levantam, ainda que os autores até possam estar certos.

Vejamos aqueles casos que nos parecem mais marcantes.

A árula que abordámos nos pontos 1 e 2, consagrada a $L$. Aquitibus, é natural que seja dedicada a Laribus, desfazendo-se a dúvida colocada a propósito da inscrição $n$. $^{\circ} 9$, que é apresentada de forma incompleta. Nos últimos tempos, têm aparecido outros textos epigráficos com a sigla $\mathrm{L}$, que surge em contextos religiosos indígenas, devendo expressar um fenómeno de sincretismo. Trata-se de um assunto a merecer estudo mais aprofundado que possa esclarecer melhor esta atribuição.

$\mathrm{Na}$ inscrição n. ${ }^{\circ}$ 12, consagrada aos Lares, não conseguimos vislumbrar com a mesma segurança de R. Étienne e G. Fabre o epíteto da 1. 2, [V]ialib(us). Aliás, os autores haviam sido mais prudentes na primeira referência à peça $\left({ }^{31}\right)$, atitude que talvez devessem ter mantido. Quando muito, poderia ter-se sugerido Vialibus como hipótese de trabalho.

Outro caso também de interpretação mais delicada do que admitem R. Étienne e G. Fabre concerne o testemunho atribuído ao culto de Neto (n. $\left.{ }^{\circ} 15\right)$, que chegam mesmo a reconstituir: [DEO

${ }^{(30)}$ Os números que colocamos entre parênteses reportam-se à numeração das Fouilles $I L$

(31) Le culte, p. 223, n. 10.

Conimbriga, 26 (1987), 39-59 
MARTI/] NETO [?]. Ainda que admitamos sob reserva estar perante um testemunho religioso a Neto(?), há que retomar e aprofundar as questões colocadas por José d'Encarnação ( $\left.{ }^{32}\right)$, de forma a apurar melhor o carácter e o teor deste texto que apareceu e desapareceu na primeira metade do século xix.

$\mathrm{Na}$ inscrição $\mathrm{n} .^{\circ} 19$, admitimos estar perante um testemunho do culto de Marte (não sabemos se de Mars Augustus, como sugerem os autores), mas preferimos salientar, face ao conjunto da proposta de reconstituição do texto, a ideia dos autores de que tal deve ser feito com «beaucoup de prudence» (33).

Quanto à inscrição n. ${ }^{\circ} 20$, admitimos a viabilidade da hipótese de que seja consagrada a Apolo, mas também nos perguntamos se não poderia haver outra divindade compatível com os traços iconográficos apresentados na peça.

Mais delicadas nos parecem as opiniões de R. Étienne e G. Fabre a propósito das inscrições n. ${ }^{\text {ss }} 1,16$ e 22.

No primeiro caso $\left(\mathrm{n} .{ }^{\circ} 1\right)$, é reconhecido que «le sens de ce document est plutôt obscur» e a hipótese de que Aius seja um deus é emitida sob reserva, embora no índice figure sem interrogação. Para que fosse divindade, seria necessário encontrar o caso da consagração mais definido, além de que os traços das letras são também muito pouco claros. Na nossa opinião, trata-se de um monumento votivo de significado duvidoso.

A inscrição n. ${ }^{\circ} 16$ não nos parece que seja consagrada Phoebo Theo, como admitiram, com algumas reservas, os autores. $\mathrm{O}$ facto de haver falta de quase toda a metade direita do campo epigráfico da árula não viabiliza a sua restituição tal como é feita, tanto mais que a proposta expressa aparece sob uma forma insólita e sem paralelos. Admitimos que se trata de um monumento votivo, mas de carácter incerto.

Quanto à inscrição n. ${ }^{\circ} 22$, apesar de os autores avançarem com uma hipótese de interpretação «avec beaucoup de prudence» (3á),

(32) Divindades indígenas sob o domínio romano em Portugal, Lisboa, Imprensa Nacional-Casa da Moeda, 1975, p. 248-250.

(33) Fouilles //, p. 40.

(34) Fouilles //, p. 45. 
parece-nos, ainda assim, que ela é demasiado aventurosa, para ser sustentável a possibilidade de estarmos perante um testemunho Matri Deum. Os vestígios de letras deste monumento votivo são demasiado escassos. Por outro lado, as rosetas que decoram a ara não aparecem apenas nos monumentos a Cibele, pelo que tal argumento não pode servir para reforçar uma hipótese demasiado frágil.

Finalmente, desejaríamos afirmar uma opinião que expressámos no início deste ponto 3 , segundo a qual não nos parece prudente classificar entre as inscrições votivas a peça $n .^{\circ} 5$, que foi atribuída ao culto de Fortuna com segurança. Não nos parece que os autores consigam provar que os dois pequenos fragmentos de uma placa onde se lê um F, num, e um $\mathrm{N}$ antecedido de um $\mathrm{V}$ fracturado, noutro, sejam necessariamente parte de uma inscrição votiva à deusa Fortuna. Em nossa opinião, não há elementos suficientemente probativos para darem consistência epigráfica justificativa da inclusão destes fragmentos na secção votiva. Já no que diz respeito à consagração Pietati Augusti (n. ${ }^{\circ}$ 17), parece haver dados bastantes para admitir a hipótese de atribuição aí feita.

(35) Embora sem procurar alargar estas notas, não podemos deixar passar a oportunidade de apontar alguns lapsos que detectámos nas Fouilles II: na pág. 20, alude-se a uma inscrição a Apoio de Idanha-a-Velha que é falsa (ou, pelo menos, não é nada segura a forma como nos chegou); na pág. 21, o dedicante tem o cognomem de Sailcius e não Sanecius como aí se lê; na pág. 23 n. 32, a inscrição referente a Fortuna (CIL II $331=$ RAP 252) não é de Lisboa mas sim das ruínas de Beselga, Torres Novas; na pág. 40, refere-se o nome de Ceio como sendo um teónimo, o que não parece correcto, apesar de haver alguma dificuldade em interpretar a parte da inscrição do Castro de Três Rios onde tal nome aparece. 


\section{PRINCIPAIS ABREVIATURAS}

AP «O Arqueólogo Português», Lisboa.

CIL II Emilio HüBner, Corpus Inscriptionum Latinarum, vol. II, Berlim, 1869; Supplementum, 1892.

Le culte J. Alarcão, R. Étienne et G. FABre, Le culte des Lares à Conimbriga [Portugal), «Comptes Rendus de l'Académie des Inscriptions et Belles Lettres», Paris, 1969, p. 213-236.

Fouilles II R. Étienne, G. Fabre, P. et M. Lévêque, Fouilles de Conimbriga, II, Épigraphie et sculpture, Paris, 1976.

Obras, IV Vergilio Correia, Obras, vol. IV (Estudos Arqueológicos), Coimbra, Acta Universitatis Conimbrigensis, 1972.

RAP José Manuel Garcia, Religiões Antigas de Portugal - Fontes epigráficas, Lisboa, Imprensa Nacional-Casa da Moeda (no preio).

Fotografías

de Guilherme Cardoso

Conimbriga, 26 (1987), 39-59 